\title{
SPATIAL CONTRAST SENSITIVITY OF DARK-REARED CATS WITH STRIATE CORTEX LESIONS ${ }^{1}$
}

\author{
STEPHEN LEHMKUHLE, ${ }^{*}$ S. M. SHERMAN, $\ddagger^{2}$ AND KENNETH E. KRATZ§ \\ *Department of Psychology, Brown University, Providence, Rhode Island 02912, $\ddagger$ Department of Neurobiology and Behavior, \\ State University of New York, Stony Brook, New York 11794, and \$Department of Anatomy, Louisiana State University Medical \\ Center, New Orleans, Louisiana 70112
}

Received July 20, 1983; Revised February 21, 1984; Accepted April 4, 1984

\begin{abstract}
We measured the spatial contrast sensitivity of two dark-reared cats before and after bilateral ablations of area 17 and parts of area 18. These lesions produced large deficits in the contrast sensitivity of both cats at intermediate and high spatial frequencies. This postoperative reduction in contrast sensitivity in dark-reared cats is relatively similar to the sensitivity deficits produced by the same cortical lesions in normally reared cats. However, both pre- and postoperatively, the normally reared cats exhibited contrast sensitivity that is clearly superior to that of the dark-reared cats. The results demonstrate both that striate cortex is significantly involved in the spatial contrast sensitivity of dark-reared cats and that dark rearing produces widespread deficits, independent of those in striate cortex, through much of the visual system.
\end{abstract}

The role of striate cortex in pattern vision has been a subject of considerable interest (for reviews of this literature, see Doty, 1973; Sprague et al., 1981). Although the magnitude of the effect of striate lesions on pattern sensitivity varies among species, the postoperative deficits in cats are relatively moderate and seem to be limited to a mild reduction in visual acuity and spatial localization (Doty, 1973; Berkley and Sprague, 1979; Lehmkuhle et al., 1982). Such lesions may reduce binocular depth discrimination as well (Kaye et al., 1981).

The possible contribution of striate cortex to the integrity of pattern vision also bears upon any physiological interpretation of the pattern deficits exhibited behaviorally by visually deprived cats. There are a multitude of physiological deficits in the striate cortex of visually deprived cats (reviewed in Movshon and Van Sluyters, 1981; Sherman and Spear, 1982), and these marked physiological abnormalities are often related to the severely impaired pattern vision of these cats (Ganz and Fitch, 1968; Dews and Wiesel, 1970; Blake and DiGianfilippo, 1980; Lehmkuhle et al., 1982; and many others). However, since normally reared cats without striate cortex exhibit pattern vision and spatial contrast sensitivity that is superior to that exhibited by visually deprived cats, it follows that there must be deficits in addition to those in striate cortex that account for the largely inferior vision of visually deprived cats (Lehmkuhle et al., 1982).

Although this comparison between normally reared cats with striate lesions and deprived cats suggests that deficits in subcortical and/or extrastriate areas must be considered in order to account completely for the impaired vision of visually de-

\footnotetext{
${ }^{1}$ This research was supported by Public Health Service Grants EY03534 and EY03038.

${ }^{2}$ To whom correspondence should be addressed.
}

prived cats, these comparisons do not indicate the extent to which the abnormal physiology of striate cortical cells contributes to their abnormal vision. One possible way to study the contribution of striate cortex to the impaired pattern vision of visually deprived cats is to evaluate the behavioral consequences of ablating striate cortex in these animals.

Aarons et al. (1963) performed an analogous study in darkreared cats. They lesioned striate cortex in normally reared and dark-reared cats and measured the animals' postoperative retention of a previously learned intensity discrimination. They found that both light-reared and dark-reared cats failed to retain the intensity discrimination following the lesion. This suggests a contribution of striate cortex in the visually deprived cats that might seem surprising in view of the abnormalities evident in this cortex. However, these results are difficult to interpret within the present context for several reasons. First, the study dealt with an intensity discrimination rather than a pattern discrimination; and second, the study primarily measured retention performance and not visual sensitivity. We repeated the study on dark-reared cats with several important modifications. First, we measured pattern sensitivity by obtaining spatial contrast sensitivity functions; and second, we focused on measuring visual sensitivity and not on rates of learning. The present report describes the effects of striate cortex lesions on spatial sensitivity of dark-reared cats, and these are rather similar to the effects of such lesions in normally reared cats (Lehmkuhle et al., 1982).

\section{Materials and Methods}

Subjects. Two cats, born and reared in the colony, were kept in total darkness until 5 months of age, at which time they were housed in a normally illuminated animal colony. Their behavioral training began at about 9 months of age. Preoperative data from these cats, as well as relevant psychophysical data from other cats, were published in Lehmkuhle et al. (1982). 
Behavioral procedures. We used the method of conditioned suppression to obtain estimates of spatial contrast thresholds. The method is described in detail elsewhere (Loop and Berkley, 1972; Blake and Camisa, 1977). Briefly, each cat was trained to lick a metal tube through which small amounts of pureed beef were delivered. The lick tube was situated in front of a cathode ray tube display that subtended 17 by $18^{\circ}$ at the cat's viewing distance of $27 \mathrm{~cm}$. Retinoscopy verified that the cats used in this study were emmetropic, and $27 \mathrm{~cm}$ is beyond such a cat's near point (Bloom and Berkley, 1977). We electronically monitored the licks. Once a stable lick rate was established (approximately two licks per second), the cat was trained to suppress licking during a 10 -sec presentation of a high contrast, sinewave grating. The contrast of the grating was sinusoidally modulated in time at a rate of $1.5 \mathrm{~Hz}$. This grating always replaced a homogeneous field of the same mean luminance $\left(15.2 \mathrm{~cd} / \mathrm{m}^{2}\right)$. A mild, unavoidable electric shock was administered through the grids of the floor of the operant chamber at the end of the grating presentation. After several weeks of training, the cat would reliably suppress its lick rate during the presence of the high contrast grating. We calculated a suppression ratio as the number of licks during the 10 -second period that the grating was present divided by the number of licks during a 10 -sec period prior to grating presentation when the display was homogeneous. The training phase terminated when the suppression ratio was 0.4 , averaged across 15 or more trials for three consecutive daily sessions.

Once the cats were trained, contrast thresholds were estimated using a modified staircase procedure (for details see Blake and Camisa, 1977; Lehmkuhle et al., 1982). Briefly, if the cat detected the grating on any given trial, as indicated by a suppression ratio of 0.5 or less, the grating contrast was reduced on the next trial. If the cat failed to detect the grating (i.e., a suppression ratio greater than 0.5 ), the contrast was increased on the next trial. The changes in contrast were made progressively smaller as the staircase proceeded. We arbitrarily defined the contrast threshold as the average of the bottom steps of the last three reversals of the staircase. We used a constant temporal frequency of $1.5 \mathrm{~Hz}$ and kept the spatial frequency constant within a daily session. We typically measured two contrast thresholds for each spatial frequency and used their average as the threshold value. When the difference between these two thresholds differed by more than $0.1 \mathrm{log}$ unit, a third value was obtained, and we used the average of all three as the threshold value.

Surgical procedures. Upon completion of the preoperative testing, bilateral cortical lesions were placed in the two dark-reared cats. The surgical methods used have been described previously (Sherman, 1977; Lehmkuhle et al., 1982) and are briefly noted here. We performed surgery under aseptic conditions. The cats were anesthetized with sodium pentobarbitol. A large craniotomy was made, and the dura was reflected to expose bilaterally the posterior two-thirds of the cerebral cortex. We stored the flap of the removed bone in saline for replacement at the end of the surgery. Based on maps of cortex (e.g., Tusa et al., 1978), area 17 and a portion of the adjacent area 18 were bilaterally removed by aspiration. Gelfoam was then packed into the ablated region. The dura was reflected over the lesion and covered by the Gelfoam and bone flap. We then closed the wound with sutures and wound clips.

Each cat was subsequently retested at about 3 and 9 months postoperatively. Following this testing, the two cats were deeply anesthetized with sodium pentobarbitol and perfused transcardially with physiological saline followed by $10 \%$ formalin in saline. The brains were removed, embedded in egg yolk, and sectioned coronally at $40 \mu \mathrm{m}$. The sections were alternately stained either for myelin or Nissl substance to ascertain the extent of the cortical lesions. We reconstructed the lesions from a combination of the appearance of cortex as well as the pattern of retrograde degeneration seen in the lateral geniculate nucleus.

\section{Results}

Preoperative visual performance. The generally poor visually guided behavior and spatial contrast sensitivity functions obtained from the two dark-reared cats preoperatively have been reported previously (Lehmkuhle et al., 1982) and are shown in Figure 1. These preoperative contrast sensitivity functions are quite similar to those obtained by Blake and DiGianfilippo (1980). Sensitivity of both cats peaks near 0.5 cycle/degree and declines at lower and higher spatial frequencies. Compared to

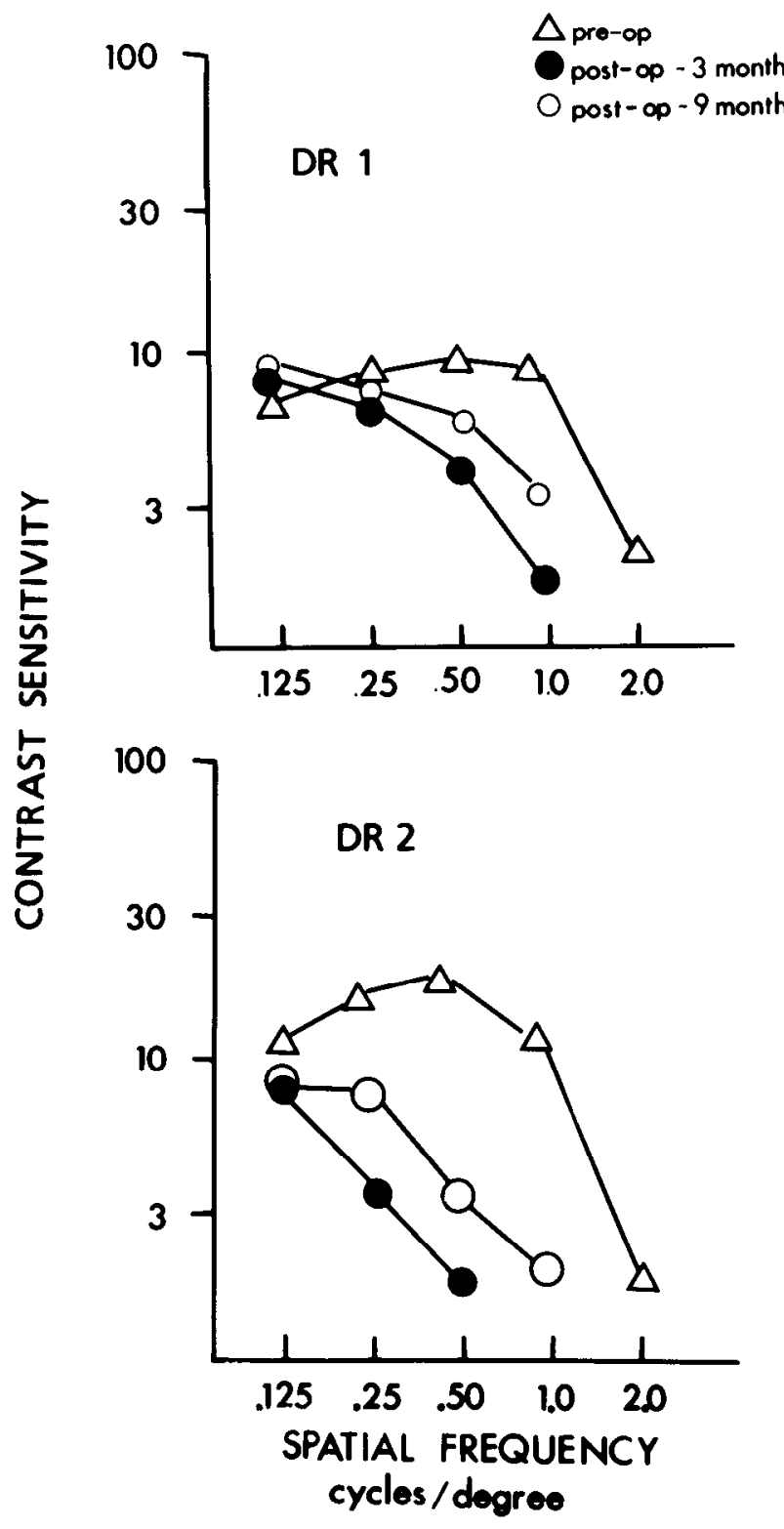

Figure 1. Spatial contrast sensitivity functions of two dark-reared cats (DR1 and $D R 2$ ) before (open triangles) and roughly 3 months (solid circles) and 9 months (open circles) after an ablation of area 17 and part of 18. Functions for DR1 are shown in the upper figure, and functions for DR2 are shown in the lower figure. Contrast sensitivity (the reciprocal of the contrast threshold) is plotted on the ordinate, and spatial frequency (cycles per degree of visual angle) is plotted on the abcissa.

that of normal cats, the sensitivity of both dark-reared cats is reduced at all spatial frequencies. However, this reduction is less at higher than at lower spatial frequencies (see Fig. 4).

Extent of cortical lesions. The cortical lesions in the darkreared cats were assessed by examination of the cortical tissue and the pattern of retrograde degeneration seen in the $A$ laminae of the lateral geniculate nuclei (Figs. 2 and 3). Although variability clearly exists in the extent of these lesions, they were quite similar for the two cats.

In each animal, the border between areas 17 and 18 was fairly completely ablated, and thus the extent of damage to area 18 had to be assessed largely from the pattern of retrograde changes in the A-laminae in the context of Sanderson's (1971) retinotopic maps of the A-laminae. It is possible to distinguish 
two types of retrograde degeneration there (Garey and Powell, 1967), although these types are not separately illustrated in Figures 2 and 3 . Lesions to area 17 alone spare many large cells in the A-laminae from degeneration, whereas conjoint lesions to areas 17 and 18 cause nearly all cells to degenerate in the retinotopically appropriate portion of the A-laminae.

For both cats DR1 and DR2, the cortical lesions seem to involve practically all of area 17 bilaterally except for variable amounts in the splenial sulcus that represent the upper and lower peripheral fields. Also, except for the extreme upper field, the border between areas 17 and 18 was completely obliterated. This included variable damage to area 18 representing a strip of several degrees of visual field adjacent to the vertical meridian.

Not only were the lesions of cats DR1 and DR2 quite similar to each other, they also were practically equivalent to analogous lesions made in normally reared cats previously described (Lehmkuhle et al., 1982; compare Figs. 2 and 3 of the present study with Figs. 5 to 8 of our prior report). The behavioral data of these normally reared cats are recapitulated below for comparison with those of the dark-reared cats.

Postoperative visual performance. The overall poor visually guided behavior of the dark-reared cats was still evident postoperatively. Figure 1 illustrates the spatial contrast sensitivity functions of the dark-reared cats at 3 and 9 months after the cortical lesions, and Figure 4 shows the sensitivity losses due to the lesions. The lesions in both cats led to marked reductions in sensitivity to middle and higher spatial frequencies but not to lower spatial frequencies. Also, a slight improvement in sensitivity was noted for both cats between 3 and 9 months postoperatively.

\section{Discussion}

\section{Effects of striate cortex lesions in dark-reared cats}

The purpose of this study was to evaluate the contribution of striate cortex to the residual vision exhibited by dark-reared cats. We found that striate lesions in dark-reared cats significantly impaired spatial contrast sensitivity, but only for intermediate and high spatial frequencies. Sensitivity at low spatial frequencies was not affected by the lesions. This observation suggests that striate cortex of dark-reared cats does subserve spatial sensitivity at middle and high spatial frequencies but plays less of a role in determining sensitivity at low spatial frequencies. It is perhaps somewhat surprising that this cortex in a dark-reared cat, that is, cortex with such abnormal physiological properties (Van Sluyters and Movshon, 1981; Sherman
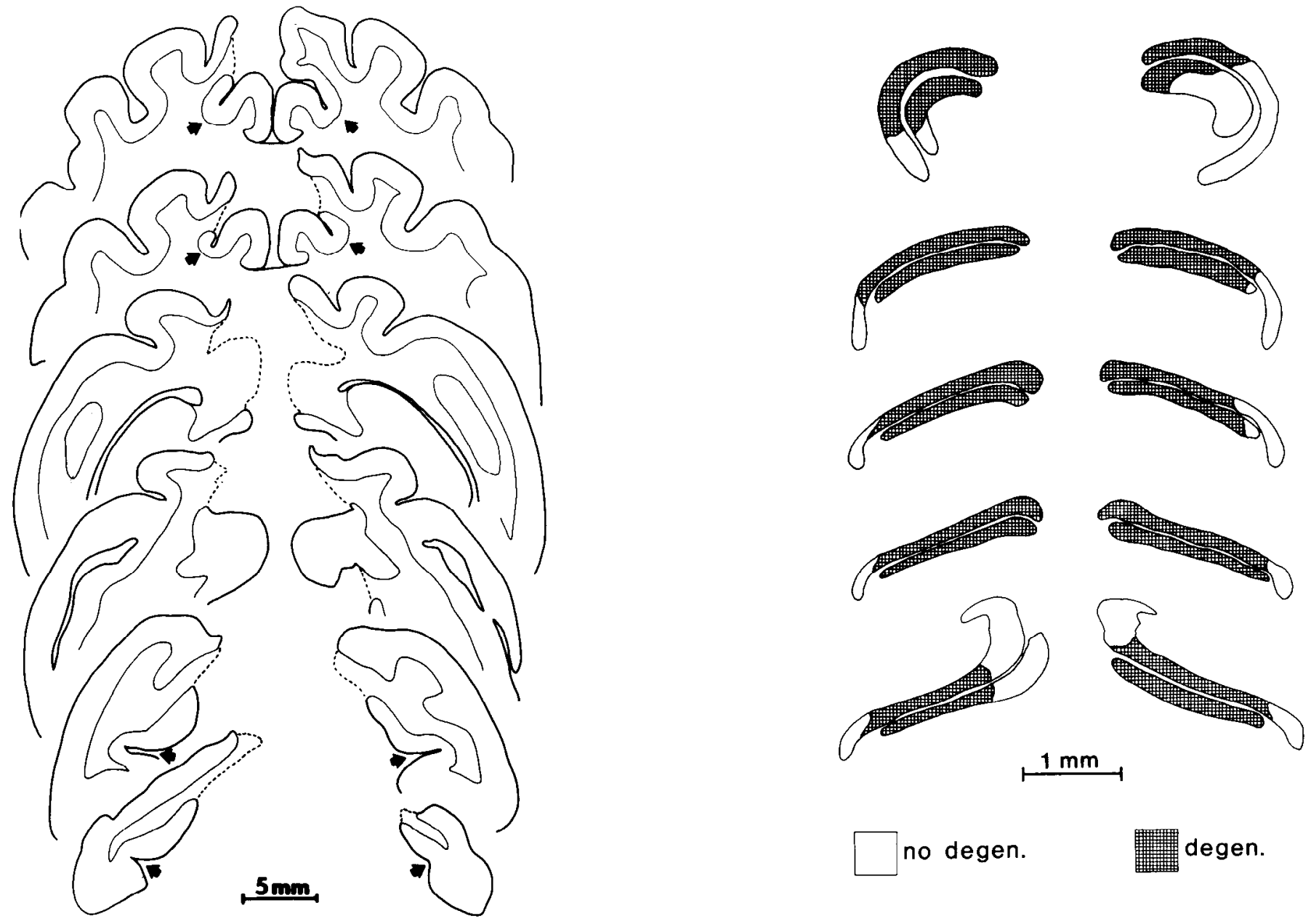

$1 \mathrm{~mm}$

Figure 2. Reconstruction of striate cortex lesion for cat DR1. Tracings of cortex through the lesion site are shown on the left side of the figure, and reconstructions of the pattern of retrograde degeneration through the A-laminae of the lateral geniculate nuclei are shown on the right side of the figure. Arrows on the left indicate the border of area 17 on the medial surface of the hemisphere; the area 17 -area 18 border on the dorsal surface was removed by the lesion. On the right side, zones of degeneration and no degeneration are indicated through the A-laminae. The pattern of retrograde degeneration correlates well with the damage evident in the cortex. See the text for details. 
and Spear, 1982), would be so useful to the cat's visual performance.

The average contrast sensitivity functions for normally reared and dark-reared cats before and after ablation of area 17 and parts of 18 are shown in Figure $4 A$. The data from the normally reared cats were previously published (Lehmkuhle et al., 1982) and represent the average for two cats. Data are also averaged for the dark-reared cats, and we selected the 9-month postoperative data to express these differences conservatively. The differences between preoperative and postoperative sensitivities of both normally reared and dark-reared cats are depicted in Figure $4 B$. As can be seen in Figure 4, the change in sensitivity produced by the cortical lesion is nearly equivalent for normally reared and dark-reared cats even though the preoperative sensitivities of the normally reared and darkreared cats are quite different. Consequently, the effect of such a striate cortex lesion is to reduce sensitivity only at higher spatial frequencies. Since a striate cortex lesion produces a similar relative deficit in normally reared and dark-reared cats, but the former has much better postoperative vision than does the latter, the pattern deficits preoperatively observed in darkreared cats cannot be adequately explained by considering only the physiological deficits in striate cortex (see also Lehmkuhle et al., 1982).

\section{Neural substrates of behavior in darh-reared cats}

Although many possible neurological correlates may be considered for these psychophysical data, two in particular seem worth elaborating. These two hypotheses are not mutually exclusive, nor are they the only hypotheses that might be considered.

Generalized cortical deficits. The simpler hypothesis is that most or all areas of visual cortex may develop abnormally to roughly the same extent during dark rearing. For example, this may occur as the result of a general failure of thalamocortical circuits to develop during dark rearing. Each visual cortical area may consequently provide a reduced but useful degree of visual processing, and lesions in any of them might provide deficits that, in relative terms, are similar to those seen in normally reared cats following equivalent lesions. Thus, striate cortex does not develop normally in dark-reared cats, but it does provide these animals with a measure of useful sensitivity to higher spatial frequencies.

Deficits in the $Y$ cell pathway. A somewhat different explanation may be found by considering deficits in the parallel W, $\mathrm{X}$, and Y cell geniculocortical pathways (Rodieck, 1979; Stone et al., 1979; Lennie, 1980; Sherman and Spear, 1982; Sherman, 1984). On the basis of a variety of physiological, morphological, and behavioral observations, the following hypothesis was proposed (reviewed in Sherman, 1984). The Y cell pathway is involved in basic form analysis from information carried in the lower spatial frequencies, and the $\mathrm{X}$ cell pathway is involved in an analysis of fine details via the higher spatial frequencies. Least is known about the W cell pathway; no specific role has yet been suggested for it in form vision (however, see Stone et al., 1979), and virtually nothing is known regarding the physiological consequences of visual deprivation on development of the $\mathrm{W}$ cell pathway. Thus, discussion below is limited to the $\mathrm{X}$ and $Y$ cell pathways.

Two observations are central to the above hypothesis for the $\mathrm{X}$ and $\mathrm{Y}$ cell pathways. The first is that geniculate $\mathrm{X}$ cells project exclusively or nearly so to striate cortex, while the $Y$ cell projection involves many extrastriate as well as striate cortical areas (Stone and Dreher, 1973; Raczkowski and Rosenquist, 1983; reviewed in Sherman, 1984). The second is that striate cortex lesions, which, thus, effectively remove the $\mathrm{X}$ cell pathway from cortical circuitry but leave much of the $\mathrm{Y}$ cell
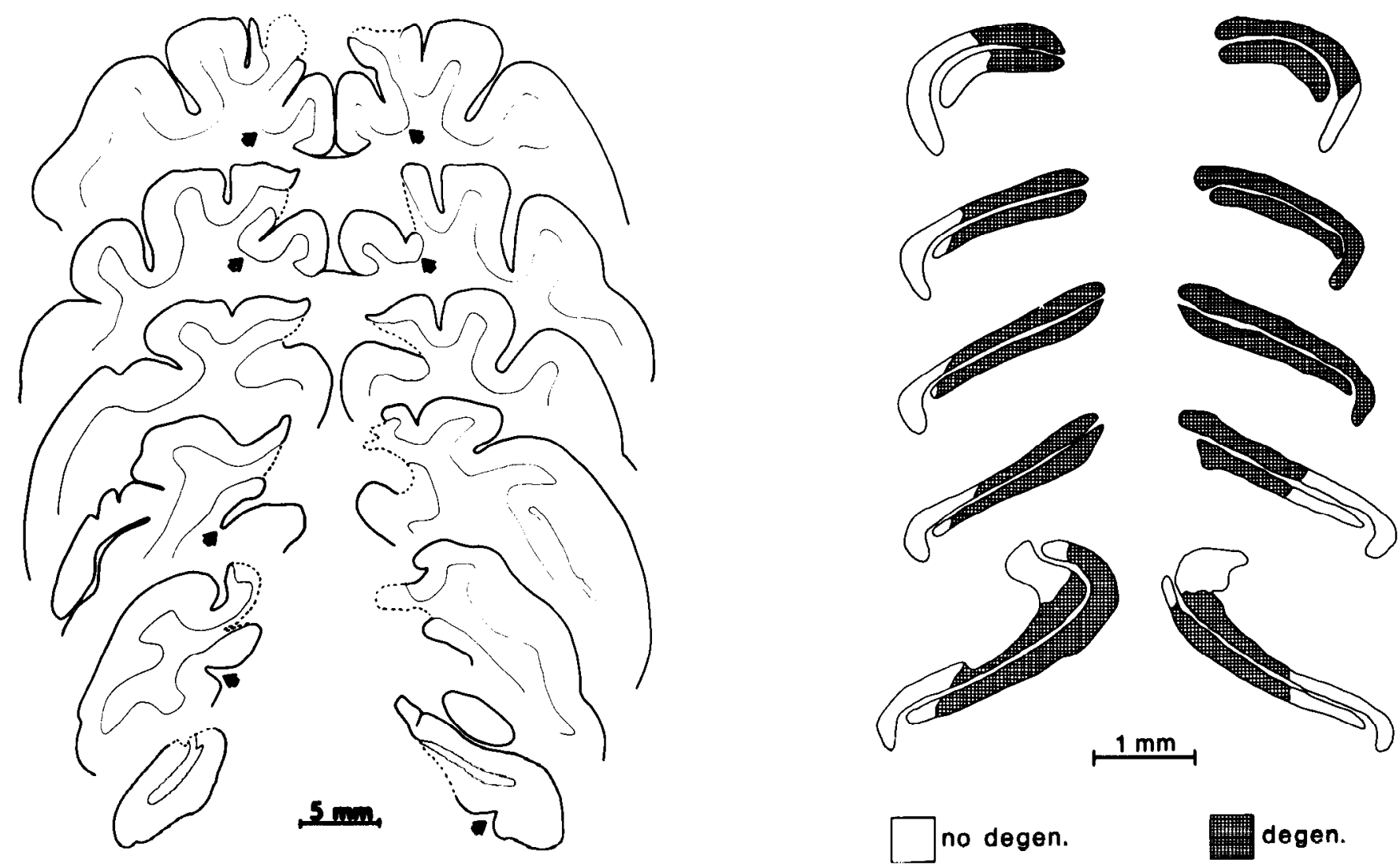

Figure 3. Reconstruction of striate cortex lesion for cat DR2. Conventions are the same as in Figure 2. See the text for details. 

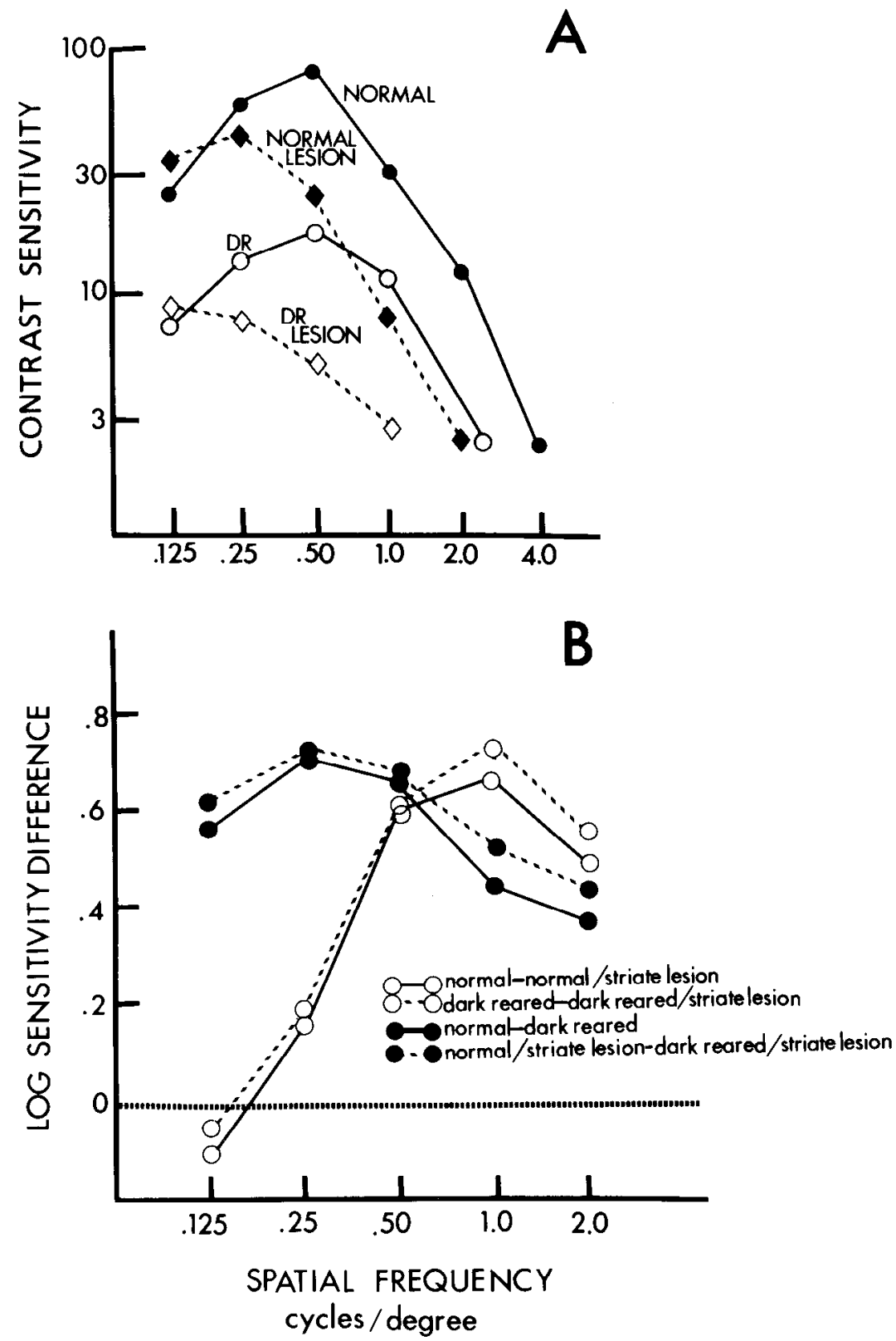

Figure 4. A, Averaged spatial contrast sensitivity functions for normally reared cats (solid circles, solid lines), dark-reared cats (open circles, solid lines), normally reared cats with cortical lesions (solid diamonds, dashed lines), and dark-reared cats with cortical lesions (open diamonds, dashed lines). There are two cats in each group. Contrast sensitivity is plotted on the ordinate and spatial frequency on the abcissa. $B$, Log sensitivity differences between different groups of cats are plotted as a function of spatial frequency. The contrast sensitivity of each group is shown in $A$. The function with open circles and solid lines depicts the difference in contrast sensitivity of normally reared cats before and after cortical lesions. The function with open circles and dashed lines shows the difference in sensitivity of dark-reared cats before and after cortical lesions. The function with solid circles and solid lines depicts the preoperative sensitivity difference between normally reared and darkreared cats. The function with solid circles and dashed lines depicts the sensitivity difference between normally reared and dark-reared cats after cortical lesions.

input intact, have surprisingly little effect on the cat's pattern vision beyond a mild acuity loss (Berkley and Sprague, 1979; Lehmkuhle et al., 1982; see also Fig. 4). Lesions that involve extensive areas of extrastriate visual cortex and, thus, most or all of the Y cell projection are needed before the cat's pattern vision is seriously compromised (Sprague et al., 1977, 1981).

According to this hypothesis, any procedure that deleteri- ously affects the $\mathrm{Y}$ cell pathway should compromise basic form vision and reduce sensitivity to lower spatial frequencies. Visual deprivation of form vision generally causes developmental abnormalities among geniculate $\mathrm{Y}$ cells (reviewed in Sherman and Spear, 1982). Indeed, dark rearing leads to the development of few normal geniculate Y cells (Kratz et al., 1979). Although geniculate $\mathrm{X}$ cells develop fairly normally in these cats (Kratz, 
1982), the abnormalities that develop in striate cortex during dark rearing suggest that the $\mathrm{X}$ cell pathway, at least at the cortical level, may be rather abnormal in these cats. Nonetheless, Blake and DiGianfilippo (1980) concluded that the darkreared cats of their study provided psychophysical evidence of rather more normal functioning of the $\mathrm{X}$ cell pathway than of the $\mathrm{Y}$ cell pathway.

This conclusion is consistent with our own data as presented here and previously (Lehmkuhle et al., 1982; see also Fig. 4). The qualitatively poor visually guided behavior of dark-reared cats and their relative insensitivity to lower spatial frequencies are consistent with their poor development of geniculate $\mathrm{Y}$ cells. Also, striate cortex lesions, which effectively eliminate any remaining function of the $\mathrm{X}$ cell pathway, further reduce their visual sensitivity, particularly with regard to stimuli of higher spatial frequencies.

It must be emphasized that, while the psychophysical data presented here may be consistent with greater physiological deficits in the $\mathrm{Y}$ cell pathway than in the $\mathrm{X}$ cell pathway, this is hardly proof of such a relationship. Furthermore, this notion and that of a generalized effect of dark rearing throughout multiple areas of visual cortex described above are not mutually exclusive. Indeed, since the geniculocortical Y cell pathway innervates so many areas of visual cortex, including striatc cortex (see Sherman, 1984), any deficits due to dark rearing among geniculate $\mathrm{Y}$ cells may well be reflected as a generalized effect throughout visual cortex.

\section{Summary}

The major finding of the present study is that striate cortex does significantly contribute to the residual spatial contrast sensitivity of dark-reared cats. Thus, striate cortex in such cats, cortex which contains cells with many abnormal response properties (reviewed in Movshon and Van Sluyters, 1981; Sherman and Spear, 1982), can subserve some pattern vision. Since striate cortex lesions have relatively similar consequences on the spatial contrast sensitivity of normally reared and darkreared cats, it is possible that the striate cortex of dark-reared cats contributes in a surprisingly normal fashion to the form vision of these cats. Furthermore, since normally reared cats after striate lesions have obviously superior vision to that of dark-reared cats following similar lesions, it follows that many extrastriate deficits must also exist in dark-reared cats that are independent of abnormalities in striate cortex. The observations are consistent with widespread deficits due to dark rearing that may result from generalized thalamocortical transmission failure, relatively specific abnormalities among the $Y$ cell pathway, or perhaps other processes not considered here.

\section{References}

Aaron, S. L., H. K. Halasz, and A. H. Riesen (1963) Interocular transfer of visual intensity discrimination after ablation of striate cortex in dark-reared kittens. J. Comp. Physiol. Psychol. 56: 196-199.

Berkley, M. A., and J. M. Sprague (1979) Striate cortex and visual acuity functions in the cat. J. Comp. Neurol. 187: 679-702.
Blake, R., and J. M. Camisa (1977) Temporal aspects of spatial vision in the cat. Exp. Brain. Res. 28: 325-333.

Blake, R., and A. DiGianfilippo (1980) Spatial vision in cats with selective neural deficits. J. Neurophysiol. 43: 1197-1205.

Bloom, M., and M. A. Berkley, (1977) Visual acuity and the near point of accommodation in cats. Vision Res. 17: 723-730.

Dews, P. B., and T. N. Wiesel, (1970) Consequences of monocular deprivation on visual behavior in kittens. J. Physiol. (Lond.) 206: 437-455.

Doty, R. W. (1973) Ablation of visual areas in the central nervous system. In Handbook of Sensory Physiology, R. Jung, ed., Vol. VII/ 3B, pp. 483-511, Springer-Verlag, Berlin.

Ganz, L., and M. Fitch (1968) 'The effect of visual deprivation on perceptual behavior. Exp. Neurol. 22: 683-690.

Garey, L. J., and T. P. S. Powell (1967) The projection of the lateral geniculate nucleus upon the cortex in the cat. Proc. R. Soc. Lond. (Biol.) 169: 107-126.

Kaye, M., D. E. Mitchell, and M. Cynader (1981) Selective loss of binocular depth perception after ablation of cat visual cortex. $\mathrm{Na}$ ture 293: 60-62.

Kratz, K. E. (1982) Spatial and temporal sensitivity of lateral geniculate cells in dark reared cats. Brain Res. 43: 55-63.

Kratz, K. E., S. M. Sherman, and R. Kalil (1979) Lateral geniculate nucleus in dark reared cats: Loss of Y-cells without changes in cell size. Science 203: 1353-1354.

Lehmkuhle, S., K. E. Kratz, and S. M. Sherman (1982) Spatial and temporal sensitivity of normal and amblyopic cats. J. Neurophysiol. 48: $372-387$.

Lennie, P. (1980) Parallel visual pathways. Vision Res. 20: 561-594.

Loop, M. S., and M. A. Berkley (1972) Conditioned suppression as a psychophysical technique for the cat. Behav. Res. Methods Instrum. 4: $121-124$.

Movshon, J. A., and R. C. Van Sluyters (1981) Visual neural development. Ann. Rev. Psychol. 32: 477-522.

Raczkowski, D., and A. C. Rosenquist (1983) Connections of the multiple visual cortical areas with the lateral posterior-pulvinar complex and adjacent thalamic nuclei. J. Neurosci. 3: 1912-1942.

Rodieck, R. W. (1979) Visual pathways. Annu. Rev. Neurosci. 2: 193255.

Sanderson, K. J. (1971) The projection of the visual field to the lateral geniculate and medial interlaminar nuclei in the cat. J. Comp. Neurol. 143: 101-118.

Sherman, S. M. (1977) The effect of superior colliculus lesions upon the visual fields of cats with cortical ablations. J. Comp. Neurol. 172: $211-230$.

Sherman, S. M. (1984) Functional organization of the W-, X-, and Ycell pathways in the cat: A review and hypothesis. In Progress in Psychobiology and Physiological Psychology, J. M. Sprague and A. N. Epstein, eds., Academic Press, New York, in press.

Sherman, S. M., and P. D. Spear (1982) Organization of visual pathways in normal and visually deprived cats. Physiol. Rev. 62: 740855 .

Sprague, J. M., J. Levy, A. DiBerardino, and G. Berlucchi (1977) Visual cortical areas mediating form discrimination in the cat. J. Comp. Neurol. 172: 441-488.

Stone, J., and B. Dreher (1973) Projection of X- and Y-cells of the cat's lateral geniculate nucleus to areas 17 and 18 of visual cortex. J. Neurophysiol. 36: 551-567.

Stone, J., B. Dreher, and A. Leventhal (1979) Hierarchical and parallel mechanisms in the organization of visual cortex. Brain Res. Rev. 1: $345-394$.

Tusa, R. J., L. A. Palmer, and A. C. Rosenquist (1978) The retinotopic organization of area 17 (striate cortex) in the cat. J. Comp. Neurol. 177: $213-236$. 